\title{
Raw Ginger Composite Antioxidant with High Efficiency to Extract Vitamin C from Strawberry
}

\author{
Yanhu Guo ${ }^{1}$, Yumin Zhang ${ }^{1}$, Dabing Luo ${ }^{2 *}$, Tao $\mathrm{Ma}^{2}$ \\ ${ }^{1}$ School of Chemistry \& Environmental Engineering, Jianghan University, Wuhan, China \\ ${ }^{2}$ State Key Lab of Advanced Technology for Materials' Synthesis and Processing, Wuhan University of Technology, Wuhan, China \\ Email: JDYHYH@163.COM, ${ }^{*}$ dblaw@whut.edu.cn
}

Received March 10, 2013; revised April 10, 2013; accepted May 10, 2013

Copyright (C) 2013 Yanhu Guo et al. This is an open access article distributed under the Creative Commons Attribution License, which permits unrestricted use, distribution, and reproduction in any medium, provided the original work is properly cited.

\begin{abstract}
Raw ginger was introduced to a series of composite antioxidants. The specimens performed better efficiency than ordinary antioxidants while extracting vitamin $\mathrm{C}$ from strawberry. The results suggested that, by employing raw ginger composite antioxidant, the reservation of vitamin $\mathrm{C}$ could be $91.63 \%$ in washing process and $76.68 \%$ in squeezing process respectively. Furthermore, in squeezing process, the reservation of vitamin $\mathrm{C}$ reached $84.78 \%$ while the concentrate of raw ginger antioxidant was $0.03 \%$. The both deposits performed perfect synergy effectively. Raw ginger composite antioxidant could be the well agent to extract vitamin $\mathrm{C}$ from fruit.
\end{abstract}

Keywords: Raw Ginger; Composite Antioxidant; Synergy Effective; Strawberry; Vitamin C

\section{Introduction}

Vitamin was one of the most important nourishment for human beings. However, vitamin was synthesized by photosynthesis. Animals' body could not generate vitamin. Thus, animals can only seize vitamin from plant directly or indirectly by food chain. Since our dishes were almost cooked, vitamin was mostly destroyed by heating, making malnutrition prevalent. Hence, extract vitamin became an important project.

Strawberry inhabits rich vitamin C. It belongs to friaries, rosaceae, and ligneous plant. The fruits were colorful, fruity and sweet berry. However, the fresh strawberry was hard to reserve due to its feeble body. It is necessary to extract nutrition from the fruit. As a task, how to efficiently reserve the vitamin was put to an agenda. Researchers paid their attention to the project in the past decades. Nowadays, because vitamin $\mathrm{C}$ was fragile, antioxidant with no poison, no side-effect was introduced to process strawberry $[1,2]$. Amongst, raw ginger composite antioxidant had not been treated.

Ginger mainly grows in Asia. Scientists applied ginger as antioxidant and already got the expected results $[3,4]$. Tea could also be antioxidant. After mixing ginger and tea deposit, the association of these two component raised by comparing the effect of ordinary food additive

${ }^{*}$ Corresponding author.
EDTA and disodium hydrogen phosphate, either be the sole ginger deposit and tea deposit. Supplying the raw ginger composite antioxidant to washing and squeezing strawberry, the reservation of vitamin $\mathrm{C}$ got up.

\section{Experiments}

1) Agencies and instruments

Agencies: fresh strawberry, ginger powder, tea, vitamin C, EDTA, $\mathrm{Na}_{2} \mathrm{HPO}_{4}$, citric acid, metaphosphoric acid.

Instruments: microwave oven, 721 photometer, UV2401 photometer, RE-S2 spinning evaporimeter, DKB501 thermostat water cistern, DF110 electric balance.

2) Processing

a) Preparation of ginger composite antioxidants

Ginger deposits: $5.00 \mathrm{~g}$ ginger powder was dispersed in $80 \%$ ethanol solution. The fluid was refluxed in the Soxhlet extractor till the liquid exhibited colorless. After filtering, the extracted liquid was enriched by a spinning evaporimeter. Dry and weigh the deposit, then mingle part outcome in $50 \%$ ethanol solution to obtain the necessary concentrate ginger solution.

Tea deposits: Avoiding ray, $15.00 \mathrm{~g}$ tea was dispersed in $300 \mathrm{ml}, 65 \%$ ethanol solution at room temperature for 3 days. After filtering, the tawny extracted liquid was enriched by a spinning evaporimeter. Dry and weigh the deposit, then mingle part outcome in $50 \%$ ethanol solu- 
tion to obtain the necessary concentrate tea solution.

Ginger composite antioxidants: According to Tables 1-3, the solution with necessary content were formu-

Table 1. Reservation of vitamin $C$ in washing process at room temperature.

\begin{tabular}{|c|c|c|c|c|c|}
\hline Antioxidant & $\begin{array}{c}\text { Concentrate/ } \\
\%\end{array}$ & $\begin{array}{c}5 \\
\min / \%\end{array}$ & $\begin{array}{c}20 \\
\min / \%\end{array}$ & $\begin{array}{c}40 \\
\min / \%\end{array}$ & $\begin{array}{c}60 \\
\min / \%\end{array}$ \\
\hline \multirow{3}{*}{$\begin{array}{c}\text { Ginger } \\
\text { deposits }\end{array}$} & 0.01 & 86.82 & 86.31 & 74.12 & 69.55 \\
\hline & 0.02 & 87.43 & 86.75 & 83.83 & 80.62 \\
\hline & 0.03 & 87.92 & 87.56 & 85.73 & 82.26 \\
\hline \multirow{3}{*}{ Tea deposits } & 0.01 & 86.53 & 86.15 & 73.60 & 67.50 \\
\hline & 0.02 & 86.97 & 86.64 & 83.92 & 81.07 \\
\hline & 0.03 & 87.42 & 87.18 & 85.46 & 83.39 \\
\hline \multirow{3}{*}{$\begin{array}{l}\text { Ginger and } \\
\text { tea deposits }\end{array}$} & 0.01 & 90.26 & 90.15 & 88.51 & 86.74 \\
\hline & 0.02 & 98.64 & 98.24 & 96.25 & 90.85 \\
\hline & 0.03 & 98.91 & 98.76 & 97.18 & 91.63 \\
\hline \multirow{3}{*}{ EDTA } & 0.01 & 86.49 & 79.20 & 78.85 & 70.65 \\
\hline & 0.02 & 86.73 & 79.83 & 79.52 & 77.19 \\
\hline & 0.03 & 87.36 & 81.56 & 80.05 & 78.23 \\
\hline \multirow{3}{*}{$\mathrm{Na}_{2} \mathrm{HPO}_{4}$} & 0.2 & 86.32 & 77.25 & 72.56 & 67.30 \\
\hline & 0.4 & 86.51 & 77.29 & 72.64 & 67.52 \\
\hline & 0.6 & 86.73 & 77.30 & 72.67 & 67.51 \\
\hline Pure water & - & 86.25 & 76.13 & 71.58 & 66.24 \\
\hline
\end{tabular}

Table 2. Reservation of vitamin $\mathrm{C}$ in squeezing at room temperature.

\begin{tabular}{ccc}
\hline Antioxidants & Concentrate/\% & Vc reservation ration/\% \\
\hline \multirow{3}{*}{ Ginger deposit } & 0.01 & 43.15 \\
& 0.02 & 54.67 \\
& 0.03 & 56.75 \\
Tea deposit & 0.01 & 42.84 \\
& 0.02 & 53.72 \\
Ginger and tea & 0.03 & 55.98 \\
deposit & 0.01 & 56.16 \\
& 0.02 & 72.80 \\
& 0.03 & 76.68 \\
EDTA & 0.01 & 49.76 \\
& 0.02 & 53.57 \\
& 0.03 & 54.41 \\
Na $_{2}$ HPO & & 37.87 \\
Pure water & 0.01 & 38.35 \\
\hline
\end{tabular}

lated with above ginger and tea deposits.

b) Reservation of vitamin $\mathrm{C}$ in washing progress

Matured strawberry was chosen no damage and with the same size to wash by different antioxidant solution in 5 minutes. The content of vitamin $\mathrm{C}$ was determined according to the time table at room temperature. According to Table 1, the concentrate of antioxidant was $0.01 \%$, $0.02 \%, 0.03 \%$ respectively. And the data were the average value among 3 tests. In contrast, Table 1 also inhabited the effect of pure water.

c) Reservation of vitamin $\mathrm{C}$ in squeezing progress

After washing by pure water, matured strawberry was chosen no damage and with the same size to squeeze while different antioxidants were introduced. The squeezing time and speed were manipulated the same. Strawberry ade was poured in beaker and stirred. 90 minutes later, filter the liquid with bilayer etamine and determined the content of vitamin C. Table 2 and Figure 1 exhibit the average value amongst 3 tests.

d) Ultraviolet-visible spectrum admeasurements of deposits

Diluting the deposits of ginger and tea by carbinol, ultra-violet-visible spectrum absorption was measured. Figures 2 and 3 illustrated the results.

\section{Results and Discussion}

1) Determination of vitamin $C$

The determination of vitamin $\mathrm{C}$ adopted the Ultravio

Table 3. Specimen of ginger compound antioxidant.

\begin{tabular}{cccccccc}
\hline Number & $\mathbf{1}$ & $\mathbf{2}$ & $\mathbf{3}$ & $\mathbf{4}$ & $\mathbf{5}$ & $\mathbf{6}$ & $\mathbf{7}$ \\
Ginger deposits/mg & 40 & 36 & 34 & 32 & 30 & 28 & 26 \\
Tea deposits/mg & 0 & 4 & 6 & 8 & 10 & 12 & 14 \\
Number & $\mathbf{8}$ & $\mathbf{9}$ & $\mathbf{1 0}$ & $\mathbf{1 1}$ & $\mathbf{1 2}$ & $\mathbf{1 3}$ & \\
Ginger deposits/mg & 24 & 22 & 20 & 23.5 & 23 & 22.5 & \\
Tea deposits/mg & 16 & 18 & 20 & 16.5 & 17 & 17.5 & \\
\hline
\end{tabular}

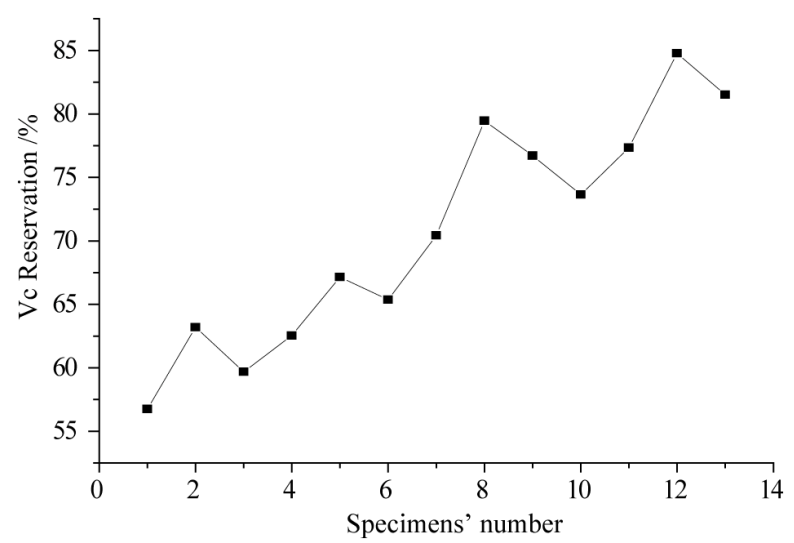

Figure $1 . V_{c}$ reservation in squeezing process. 


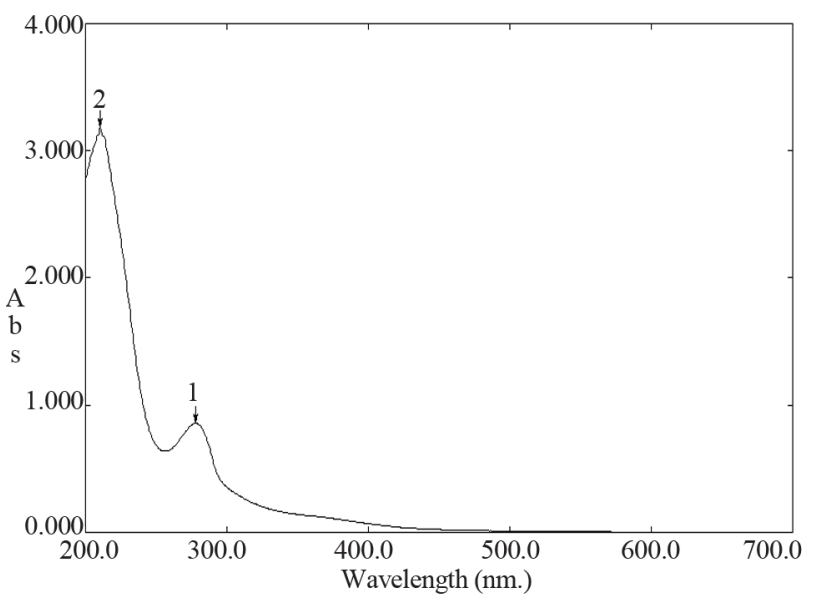

Figure 2. UV-visible absorption spectrum of methanol ginger.

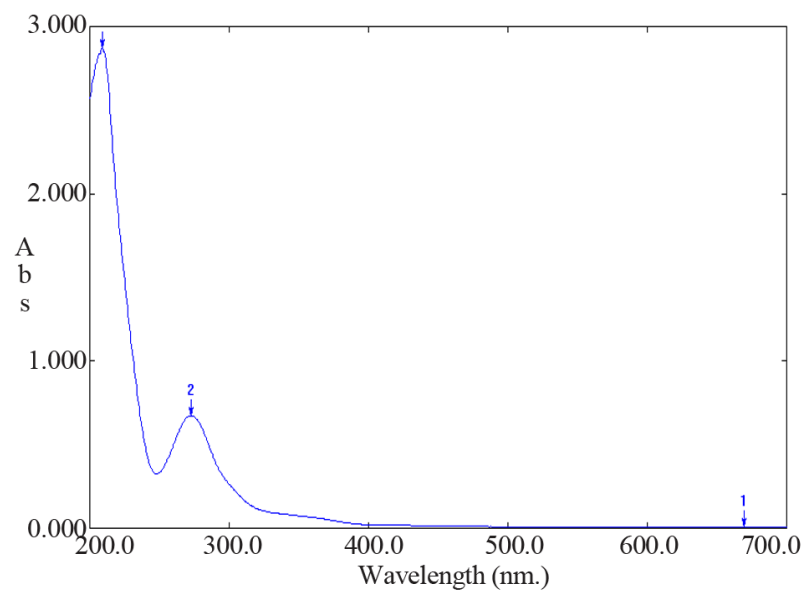

Figure 3. UV-visible absorption spectrum of tea.

let Absorption Admeasurements [5]. The calculation equation is formula (1).

$$
Y=0.00547+0.04458 X
$$

where, $X$ refers to concentrate of ascorbic acid (Lg/ml), $Y$ refers to the gap $\Delta A$ of absorption between solution and alkali specimen.

In place of standard ascorbic acid solution, concentrate of vitamin $\mathrm{C}$ could be reckoned according Formula 1. Following, the reservation of vitamin $\mathrm{C}$ was calculated.

$$
R_{\mathrm{Vc}}=C_{\mathrm{Vc}} / C_{\mathrm{Vc} 0}
$$

where, $R_{\mathrm{Vc}}$ refers to the reservation of vitamin $\mathrm{C}, C_{\mathrm{Vc}}$ refers to the content of vitamin $\mathrm{C}$ after processing, $C_{\mathrm{Vc} 0}$ refers to the original content of vitamin $\mathrm{C}$ which determined immediately following the washing process.

2) Reservation of vitamin $C$ in washing process at room temperature

According to Table 1, after washing strawberry at 25 degree for 5 minutes, agency containing ginger deposit usually performed better reservation than others. Contrast to pure water, the reservation of vitamin $\mathrm{C}$ washed by composite ginger antioxidant was $4.01 \%-12.66 \%$ higher. As long as the standing time prolonged, all the list antioxidant took effect. While the specimens were laid up to 60 minutes, antioxidant with ginger and tea deposit took the best effect. The reservation of vitamin C was $20.50 \%$ - $25.39 \%$ higher than those washed by pure water and $13.40 \%-16.09 \%$ higher than those washed by EDTA.

Ginger deposit, tea deposit as well as EDTA somehow took the similar roles in the washing process to reserve vitamin $\mathrm{C}$. $\mathrm{Na}_{2} \mathrm{HPO}_{4}$ injected even few enhancement. Furthermore, the reservation hardly varied according to the concentrate of $\mathrm{Na}_{2} \mathrm{HPO}_{4}$. It suggested that $\mathrm{Na}_{2} \mathrm{HPO}_{4}$ not help preserving vitamin $\mathrm{C}$. However, ginger and tea composite antioxidant took the greatest effective, proving that ginger deposit associate tea deposit to reserve vitamin $\mathrm{C}$ as antioxidant. When the concentrate of composite antioxidant was $0.02 \%-0.03 \%$, the reservation of vita$\min \mathrm{C}$ was the highest in washing process.

3) Reservation of vitamin $C$ in squeezing process

In squeezing process, according to Table 2, ginger deposit, tea deposit, composite antioxidant and EDTA brought obviously higher reservation of vitamin $\mathrm{C}$, while $\mathrm{Na}_{2} \mathrm{HPO}_{4}$ took almost no effect. Amongst them, composite antioxidant performed perfect. By introducing ginger and tea composite antioxidant, concentrate of vitamin $\mathrm{C}$ in the squeezed juice enhanced $18.60 \%-39.24 \%$, also $6.4 \%-22.27 \%$ higher than that introduced EDTA. When the concentrate of composite antioxidant was $0.02 \%$ $0.03 \%$, the reservation of vitamin $\mathrm{C}$ was the highest in squeezing process.

4) Reservation of vitamin $C$ related to the content of ginger-tea antioxidant

According to Table 3, a serial of composite antioxidant were prepared. All specimens had the same mass while the contents of ginger deposit and tea composite varied. Each one was resolved $0.03 \%$ mass concentrate in water. After adding the solution in squeezing process, the content of vitamin $\mathrm{C}$ was determined by formula (1) and formula (2). Figure 1 exhibited the measurement.

Figure 1 perceived that the sequence of reservation was $12>13>8>11>9>10>7>5>6>2>4>3>1$. That meant that binary antioxidant applied more action than solo antioxidant to the reservation. While the ginger deposit was $23 \mathrm{mg}$ and tea deposit was $17 \mathrm{mg}$, reservation of vitamin $\mathrm{C}$ reached the highest $84.78 \%$.

5) UV-visible spectrum determination of ginger deposits

Figure 2 was the UV-visible absorption spectrum of methanol ginger solution. At the wavelength between $200 \mathrm{~nm}$ and $400 \mathrm{~nm}$, there exist two character absorption peaks. 1 is around $280 \mathrm{~nm}$, and 2 is around $230 \mathrm{~nm}$. These two peaks were in accordance with raw flavone [6], and also similar to the pure gingerose [7], strongly rec- 
ommend that flavone and gingerose alike exist in ginger deposit.

Figure 3 was the UV-visible absorption spectrum of tea solution. As Figure 2, at the wavelength between 200 $\mathrm{nm}$ and $400 \mathrm{~nm}$, there also exist two character absorption peaks. They were around $210 \mathrm{~nm}$ and $273 \mathrm{~nm}$ respectively. These two peaks were in accordance with tea polyphenols [8], recommend that tea polyphenols alike exist in tea deposit.

6) Anti-oxide principle

Ginger contains zingiberol, zingiberene, bisabolene, ar-curcumene $\alpha$-, $\beta$-farnesene, linalool, flavone and $e t$ al. [9]. These substances all possess phenol-oxhydryl. The main ingredient of tea deposit is tea polyphenols. It also possesses flavonoid compounds [10]. Since the phenoloxhydryl activated to supply hydrogen, vitamin C kept deoxidation in the processes. In solution, EDTA decomposed into anion $\mathrm{H}_{2} \mathrm{Y}^{2-}$, which abstracted $2^{+}$and $3^{+}$ cation, forming steady compound MY. Thus, vitamin C was protected to be oxidated due to the lack of metal cation. Further investigations included that hydro-bond existed between vitamin C and EDTA, making the vitamin keep the original structure [9].

Further study claimed that different antioxidant took on different characteristics. In strawberry, lots of hydrogen peroxide, various mineral elements and $\mathrm{H}_{2} \mathrm{O}_{2}$ not only harmed cell, but also initiated peroxidation, producing various living radicals, accelerating the oxidation of vitamin C. For ginger composite antioxidant, ginger ingredient and tea ingredient still cooperate to clear living radicals, enhanced the antioxidating action. The detail principle was investigated so far.

\section{Conclusion}

Ginger composite antioxidant was prepared and the effectiveness to reserve vitamin $\mathrm{C}$ in washing and squeezeing process was investigated. By comparing binary system and solo system, it could be inferred that tea deposit associated ginger deposit to reserve vitamin in both processes. While a mass of ginger deposit and tea deposit were $23 \mathrm{mg}$ and $17 \mathrm{mg}$ respectively, and the concentrate of antioxidant was $0.03 \%$, the reservation of vitamin $\mathrm{C}$ reached the highest $84.78 \%$.

\section{Acknowledgement}

Thank to the support of Hubei Science Research Project B20083404 and B20114504.

\section{REFERENCES}

[1] X.-H. Pan, S.-J. Guo, Y.-L. Yang, et al., "Preservation of Annona squamosa L. Fruits with Film-Coating Agent Mixed Chinese Herbal Extracts," Food Science, Vol. 30, No. 22, 2009, pp. 373-378.

[2] D. Y. Hou, R. H. Hui, X. Y. Liu, et al., "Determination of Catechin in Black Teas and Its Antioxidation Effect," Food Science, Vol. 26, No. 8, 2005, pp. 367-370.

[3] Y. Masuda, H. Kikuzaki, M. Hisamoto and N. Nakatani, "Antioxidant Properties of Gingerol Related Compounds from Ginger," BioFactors, Vol. 21, No. 1-4, 2004, pp. 293-296. doi:10.1002/biof.552210157

[4] Y.-H. Guo, J.-Y. Xu, D.-X. Cheng, et al., "In Vitro Antioxidant Activity of Natural Ginger Extract Complex," Food Science, Vol. 30, No. 22, 2009, pp. 96-100.

[5] T.-H. Tan, D.-N. Ding and W. Chen, "Background Correction Method for the Determination of Ascorbic Acid Using Direct Ultraviolet Spectrophotometer," Chinese Journal of Pharmaceutical Analysis, Vol. 11, No. 1, 1991, pp. 26-29.

[6] Y.-G. Chen, "Plant Chemical Composition," 1st Edition, Chemical Industry Publishing House, Beijing, 2004, pp. 223-239.

[7] H.-G. He, et al., "High-Performantce Liquid Chromatograhy-Electospral Mass Spectrometric Analysis of Pungent Constitutes of Ginger," Journal of Chromatography A, Vol. 769, 1998, pp. 327-334.

[8] H.-N. Huang, W.-N. Meng, L.-N. Weng, et al., "Composition, Structure and Stability of Tea Polyphenol-Manganese Revealed by RP-HPLC and MALDI-TOF Mass Spectrometry," Journal of Xiamen University (Natural Science), Vol. 47, No. 1, 2008, pp. 83-87.

[9] Y. Dang and Y. Xiao, "Traditional Chinese Medicine Health Food Research and Development," 1st Edition, People's Medical Publishing House, Beijing, 2002, pp. 129-131.

[10] W.-B. Gao and G.-B. Weng, "Anti-Oxidant Effects of Green Tea Polyphenols and Their Mechanism: Research Advances," Journal of International Pharmaceutical Research, Vol. 36, No. 5, 2009, pp. 332-335. 